\title{
Expectativa de Enseñanza de la Ética en Educación Superior
}

Cabrera Benavides, Lucero Liliana

Universidad de Nariño, Colombia luceroliliana08@hotmail.com
Mora Granja, Jairo Alexander

Universidad de Nariño, Colombia jamdiez@hotmail.com
Resumen - Expectativas de enseñanza de la ética surge de la investigación "Estado de la Enseñanza de la Ética en Educación Superior" 2017-2018 Caso programas de Licenciatura de la Universidad de Nariño. El artículo desde la parte empírica describe las expectativas de los docentes y estudiantes respecto a la enseñanza de la ética, para lo cual se realizaron entrevistas semi estructuradas. Entre los resultados se encuentra que tanto docentes y estudiantes esperan que un curso de ética relacione la teoría con la práctica de manera integral.

Palabras claves: Enseñanza de la ética, Educación superior, Docencia Universitaria Expectativas docentes, Expectativas estudiantes

Abstract - Expectations of teaching ethics arises from the research "State of the Teaching of Ethics in Higher Education" 2017-2018 Case of the University of Nariño. The article from the empirical part describes the expectations of teachers and students regarding the teaching of ethics, for which they are semistructured interviews. Among the results is that both teachers and students expect an ethics course to relate theory to practice holistically.

Keywords: Teaching of ethics, Higher education, University teaching Expectations of teachers, Expectations of students

\section{INTRODUCCIÓN}

El presente artículo se deriva del proyecto de investigación, "Estado de la Enseñanza de la Ética en Educación Superior" 2017-2018 Caso programas de Licenciatura de la Universidad de Nariño. La investigación se fundamenta en la necesidad de docentes que contribuyan al ejercicio ético en el campo laboral a partir de la socialización y la reflexión de valores.
Interconectando Saberes, 2019

ISSN: 2448-8704
Fecha de Recepción: 10 de mayo de 2019

Fecha de Aceptación: 14 de octubre de 2019

Fecha de Publicación: 31 de octubre de 2019 
Esto con el fin de promover buenas prácticas sociales desde los centros de educación superior en contraste a los problemas causados por la violencia, delincuencia y la corrupción que se evidencian a diario, en los cuales la universidad se encuentra inmersa.

La estructura del artículo es la siguiente: en un primer momento se presenta una revisión teórica relacionada a expectativas de enseñanza de la ética. Seguidamente se expone la metodología y los resultados de las entrevistas realizadas a los estudiantes y docentes, a partir de la cual se realizó una triangulación de información.

Particularmente en la revisión teórica se tuvo en cuenta el grado de afinidad y relevancia de los documentos referentes a: expectativas de enseñanza; la relevancia de la ética en la educación superior; la formación de profesionales éticos y la enseñanza de la ética a partir de las problemáticas del contexto.

Metodológicamente el estudio tiene en cuenta el enfoque cualitativo. La investigación se acompaña de entrevistas semi-estructuradas realizadas a representantes estudiantiles y directivos docentes (directores de programas y decanos) de los Programas de Licenciatura de la Universidad de Nariño con el fin de profundizar en expectativas para la enseñanza de la ética.

Entre los resultados sobre expectativas de enseñanza de la ética, se denota la importancia de la ética dentro de las universidades, donde la ética actúa como un frente a los problemas de corrupción y violencia que se presenta en los diferentes escenarios de la vida pública y privada, como se expondrá a continuación.

\section{MARCO TEÓRICO}

En el apartado se presentan referentes clásicos y contemporáneos que trabajan términos relacionados a estrategias y expectativas de enseñanza, entre ellos se encuentra Morín (1999), Nussbaum (2015), Cortina (2013), y Ospina (2012), para quienes es fundamental que la enseñanza de ética se dirija a la reflexión de problemáticas sociales y al fomento del sentido de pertenencia de las personas. 
Al entender la ética desde la educación como un proceso de socialización, se puede citar el texto los siete saberes de Morín (1999) que trata "las cegueras del conocimiento; el error y la ilusión; los principios de un conocimiento pertinente; enseñar la condición humana; enseñar la identidad terrenal; enfrentar las incertidumbre; enseñar la comprensión y la ética del género humano" (p. 72).

En cuanto el saber "enseñar la comprensión" y "la ética del género humano", Morín (1999) rescata un aspecto importante, que es: preparar a las personas para que puedan vivir en sociedad. De esta forma se requiere que desde las aulas los docentes desarrollen en los estudiantes principios y valores que les permita generar ambientes de tolerancia en base a la ética humana. (p. 73)

Otro aspecto importante que corresponde a la ética para Morín (1999), es la eficacia de los procesos educativos, donde las disciplinas deben replantear su función, la cuestión de la especialización no es dividir el conocimiento si no que a partir de cada disciplina se genere un conocimiento integral del todo.

Es decir, si se estudian las ciencias sociales no se deben desligar las ciencias naturales, así en todo un conjunto de asignaturas que correspondan a una situación real. A partir de lo cual se debe enseñar la propia condición humana, entendiendo la relación que tenemos con lo que nos rodea, "El fin es aclarar las multidimensionalidades y complejidades humanas y la necesidad de integrar el aporte inestimable de las humanidades". (Morín, 1999, p. 75)

La ética de la comprensión es un arte de vivir que nos pide, en primer lugar, comprender de manera desinteresada. Pide un gran esfuerzo ya que no puede esperar ninguna reciprocidad: aquél que está amenazado de muerte por un fanático comprende por qué el fanático quiere matarlo, sabiendo que éste no lo comprenderá jamás. Comprender al fanático que es incapaz de comprendernos, es comprender las raíces, las formas y las manifestaciones del fanatismo humano. (Morín, 1999, p. 76) 
Con la enseñanza de la comprensión humana se logra pensar en el otro y dejar a un lado los prejuicios que se crean de ellos. De esta manera se contribuye a la ética del género humano visto como desarrollo de conciencia social, generando espacio de diálogos democráticos, a partir del crecimiento de las personas humanamente. (Morín, 1999, p. 78)

Apoyando los estudios en mención esta Ospina (2012) con "la tercera piedra después del sol" donde uno de los problemas que encuentra es el enfrentamiento del hombre a sí mismo, es decir a la noción que se tiene de ser independiente, a la creencia que se tiene de ser autosuficiente.

De esta forma, la responsabilidad de las instituciones según Ospina (2012), va más allá de lo técnico y se encamina más en la formación de ciudadanos capaces de entender la grandeza de las cosas que se les brinda dentro de la globalización radical que desconoce la importancia de los valores en la integración de la sociedad.
El que aprende a celebrar las cosas del mundo y agradecerlas está en camino de ser humano y de ser ciudadano. Y esto es importante porque desde hace algún tiempo, como parte de este mero carnaval del crecimiento y la productividad que se ha apoderado del mundo, cada vez quieren más que seamos operarios y administradores, contadores y funcionarios, pero no parece haber suficientes instituciones interesadas en que seamos responsables ciudadanos $y$ verdaderos seres humanos éticos. (Ospina, 2012, p.14)

Otro estudio en España de MoraIla (2005), "La ética de las profesiones en la formación universitaria" trata el tema de la ética frente a los cambios acelerados tecnológicos y la práctica de conocimiento científico que impiden la reflexión de los valores que le sirven a su desarrollo.

No es sobre las relaciones entre la sociología de las profesiones y las facultades o escuelas universitarias. Por su función mediadora entre la investigación cientifica, la docencia especializada y la cultura de los pueblos, la universidad no puede ser únicamente una respuesta institucional a las demandas de 
Expectativa de Enseñanza de la Ética en Educación Superior

capacitación y formación que tiene una determinada sociedad. La universidad no sólo gestiona conocimiento sino que lo conmemora y produce. (Moralla, 2005, p. 39)

El estudio de Moralla (2005) se refiere a la ética como la conciencia de los individuos, diferenciándola de la deontología, que se mueve preferentemente en el campo de los criterios compartidos por el colectivo profesional. El desarrollo de una formación ética permite agrupar sentimientos colectivos, donde la comunidad adquiere más solidez "Cuando un grupo de personas que padecen una misma enfermedad se asocian para defender sus intereses y esta asociación se convierte en una asociación de autoayuda." (p. 42)

Después de varios siglos de disputas entre autores como Maquiavelo que buscaban fundamentar la ética en el ámbito político, de los cuales se han inspirado pensadores desde finales del siglo XX y comienzos del siglo XXI que teorizan acerca de las virtudes de la vida pública, donde la ética virtud emblematizada por el discurso de Sócrates y llevada a su mejor expresión en la ética aristotélica olvidada durante mu- cho tiempo durante el periodo ilustrado, vuelve a resurgir a partir de diferentes perspectivas sociales. (Moratalla, 2005, p. 46)

De igual manera, en la misma línea se tiene el duro discurso contra los gobiernos del mundo y sus políticas de educación de Nussbaum (2015), quien observa que las políticas educativas están enfocadas en la rentabilidad y la formación técnica, dejando de lado prioridades como es el desarrollo de un pensamiento y razonamiento de las problemáticas que se evidencian en la actualidad, lo cual desconoce el papel de la educación como eje de transformación.

Nussbaum (2015) plantea que ciertas habilidades están en riesgo de perderse, habilidades cruciales para la salud interna de cualquier democracia, y para la creación de una cultura mundial capaz de abordar de manera constructiva los problemas. Estas habilidades están asociadas con las humanidades y las artes: la capacidad de pensar de manera crítica; la capacidad de trascender las lealtades locales y acercarse a los problemas mundia- 
les como un "ciudadano del mundo"; y la capacidad de imaginar comprensivamente la situación del otro. (p.1)

Nussbaum (2015) comprende que los políticos ven la educación sobre todo como un medio para promover el crecimiento económico, dirigen su atención hacia una formación para el lucro y no se orienta como tal hacia el fomento de una democracia. De esta manera, el tema de la ética aparece en su amplitud con el fin de rescatar procesos reales, orientados hacia el rescate del ser humano para la sociedad.

Nussbaum (2015) concluye su discurso con la siguiente apreciación: si el verdadero choque de civilizaciones es, como creo, un choque dentro de la persona individual, todas las sociedades modernas están perdiendo rápidamente la batalla, ya que se alimentan las fuerzas que conducen a la violencia y la deshumanización y dejan de alimentar las fuerzas que conducen a cultivar la igualdad y el respeto.

Si no insistimos en la importancia crucial de las humanidades y las artes, éstas se desplomarán, porque no generan dinero. Solo hacen algo que es mucho más valioso que eso, hacen un mundo en el que vale la pena vivir, las personas que son capaces de ver a otros seres humanos como personas llenas, con pensamientos y sentimientos propios que merecen respeto y simpatia, y naciones que son capaces de superar el miedo y la sospecha en favor del debate comprensivo y motivado. (Nussbaum, 2015, p.2)

Por otra parte se tiene la obra de Cortina (2013) ¿Para qué sirve la ética?, donde resalta la necesidad indiscutible de una formación en valores dentro de una concientización social de la ciudadanía. Para Cortina si las personas desarrollaran valores a plenitud, se podría reducir costos en la sociedad, es decir si se pudiera desarrollar principios como respeto, tolerancia y responsabilidad, se mejoraría los canales de comunicación y confianza entre las personas.

Desde la visión de Cortina (2013), si hubiera confianza entre las personas, no se tendría que pagar por seguridad social, no existirían tantos ministerios de protección, se reducirías las cárce- 
les entre otros, "si fuera posible un mundo en que contara como moneda corriente la confianza en las familias, las escuelas, las organizaciones, las instituciones, la vida sería infinitamente más barata" (p.1)

En sí, la ética y su práctica permitirían mejorar diferentes temas sociales, "ahora mismo nos encontramos en episodios que no sabemos cómo afrontar, asesinatos, violaciones de derechos, criminalidad, corrupción entre otros." Cortina, 2013: 30) Sin embargó la pregunta que nos lleva el libro de Cortina sobre ética es ¿qué podemos hacer?, si bien sabemos que esto compete a las autoridades y a los gobiernos, ¿debemos ser indiferentes?

La cuestión aquí es que hacemos parte de la problemática y no podemos pasar de largo "si la gente no tomamos nota de lo cara que sale la falta de ética, en dinero y en dolor, sino nos negamos a pagar ese astronómico precio, el coste de la inmoralidad seguirá siendo imparable" (Cortina, 2013, p. 30)
En esta parte es necesario comprender que el coste de la inmoralidad que se vive en la actualidad recae sobre todo en los más débiles, quienes no cuentan con condiciones de dignidad para vivir. Es así como la solución está en la humanidad, en la forma que tengan para solucionar conflictos sin afectar ni dañar al otro.

Por último, la obra de Cortina (2013) rescata la necesidad de armarnos en ética desde los centros educativos y en la vida misma para rescatar lo que nos queda. Sí bien los problemas presentes en la sociedad dependen de entes sociales, no ahí que desconocer que la solución está en los valores que promuevan las instituciones.

En relación a las perspectivas que se tiene sobre expectativas de enseñanza es importante rescatar posturas mencionadas de Ospina (2012), Nussbaum (2015), Cortina (2013), como sus principales, respecto a la importancia de desarrollar la enseñanza de la ética de forma interdisciplinar en los diferentes campos de estudio. De igual forma, sostienen que la ética debe 
ser trasversal al aula y enfocarse en las prácticas y problemáticas a las que se deben enfrentar los futuros profesionales.

\section{MetodologíA}

La presente investigación sigue un diseño metodológico cualitativo en tanto su fin es aproximarse a expectativas que estudiantes y docentes tienen de la enseñanza de la ética en los Programas de Licenciatura de la Universidad de Nariño, a partir del uso de técnicas como la entrevista semiestructurada no estandarizada, que permite profundizar en el caso de forma contextualizada.

Se realizaron dos tipos de entrevistas de siete preguntas respectivamente aplicadas a docentes $y$ estudiantes. Las entrevistas permitieron considerar las percepciones y expectativas de los participantes de manera personalizada, donde se tiene en cuenta el punto de vista de los estudiantes y directivos docentes en cuanto a la concepción, estrategias y expectativas de enseñanza de la ética.
Respecto a la selección del caso, se tuvo en cuenta a Programas de Licenciatura de la Facultad de Educación y Ciencias Humanas, dado que al revisar los PEP se encuentra que en los objetivos y en las mallas curriculares la mayor parte de las licenciaturas cuentan con el componente de ética, siendo el foco de análisis del presente estudio. De igual forma, se consideró las licenciaturas dado que son formadoras de formadores.

La unidad de análisis son 6 directivos docentes y 5 representantes estudiantiles pertenecientes a los programas de: Licenciatura en Lengua Castellana y Literatura; Licenciatura en Educación básica con énfasis en Ciencias Naturales y Educación Ambiental; Licenciatura en Educación Básica con Énfasis en humanidades, Lengua Castellana e Inglés; Licenciatura en Inglés y Francés y Licenciatura en Filosofía y Letras de la Universidad de Nariño.

Se entrevistaron a representantes estudiantiles de los últimos semestres que han visto el curso de ética y a directivos docentes: deca- 
Expectativa de Enseñanza de la Ética en Educación Superior

Tabla 1. Guion Entrevista Estudiante

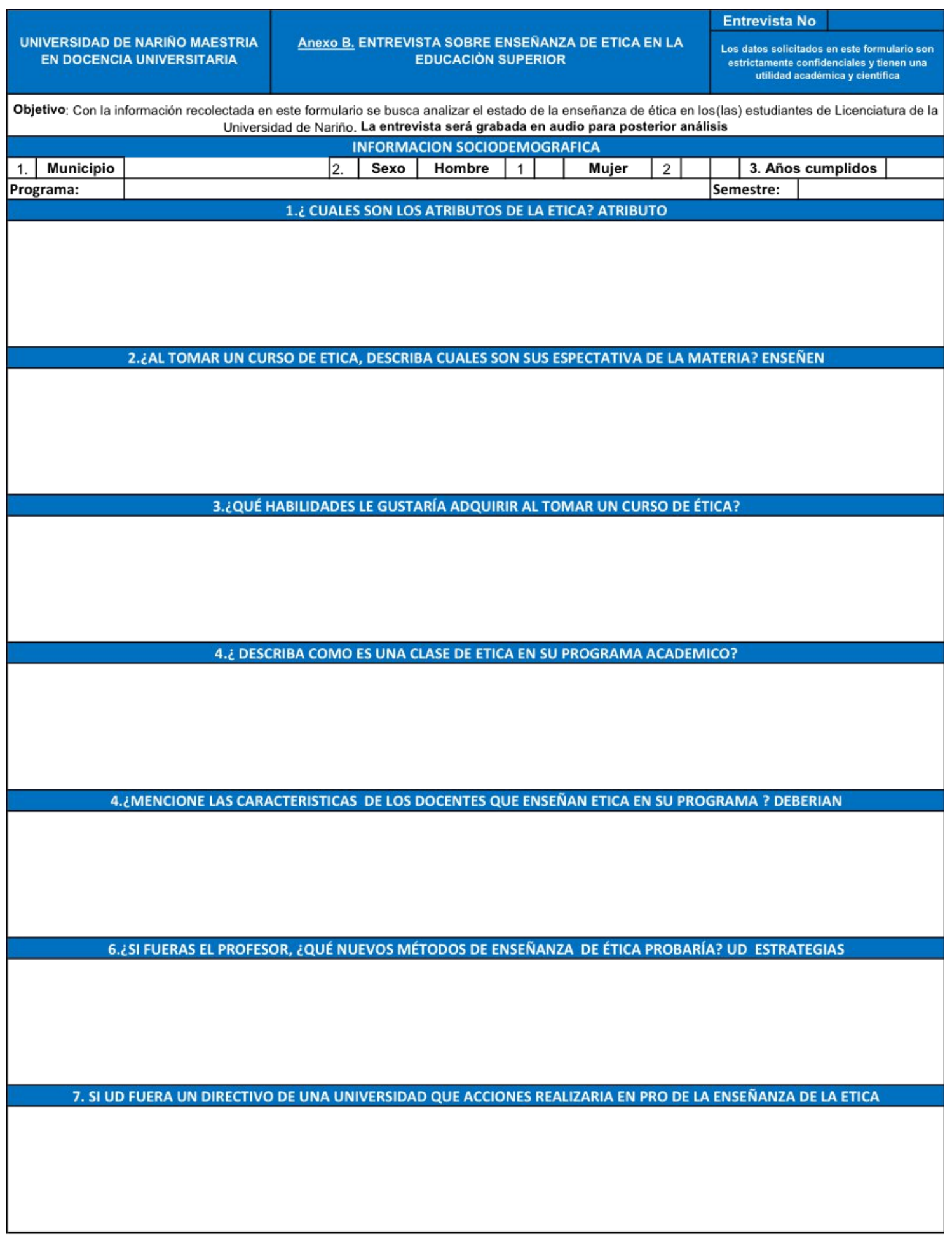

Muchas Gracias por su Colaboración.

Fuente: elaboración propia 
Tabla 2. Entrevista Docente

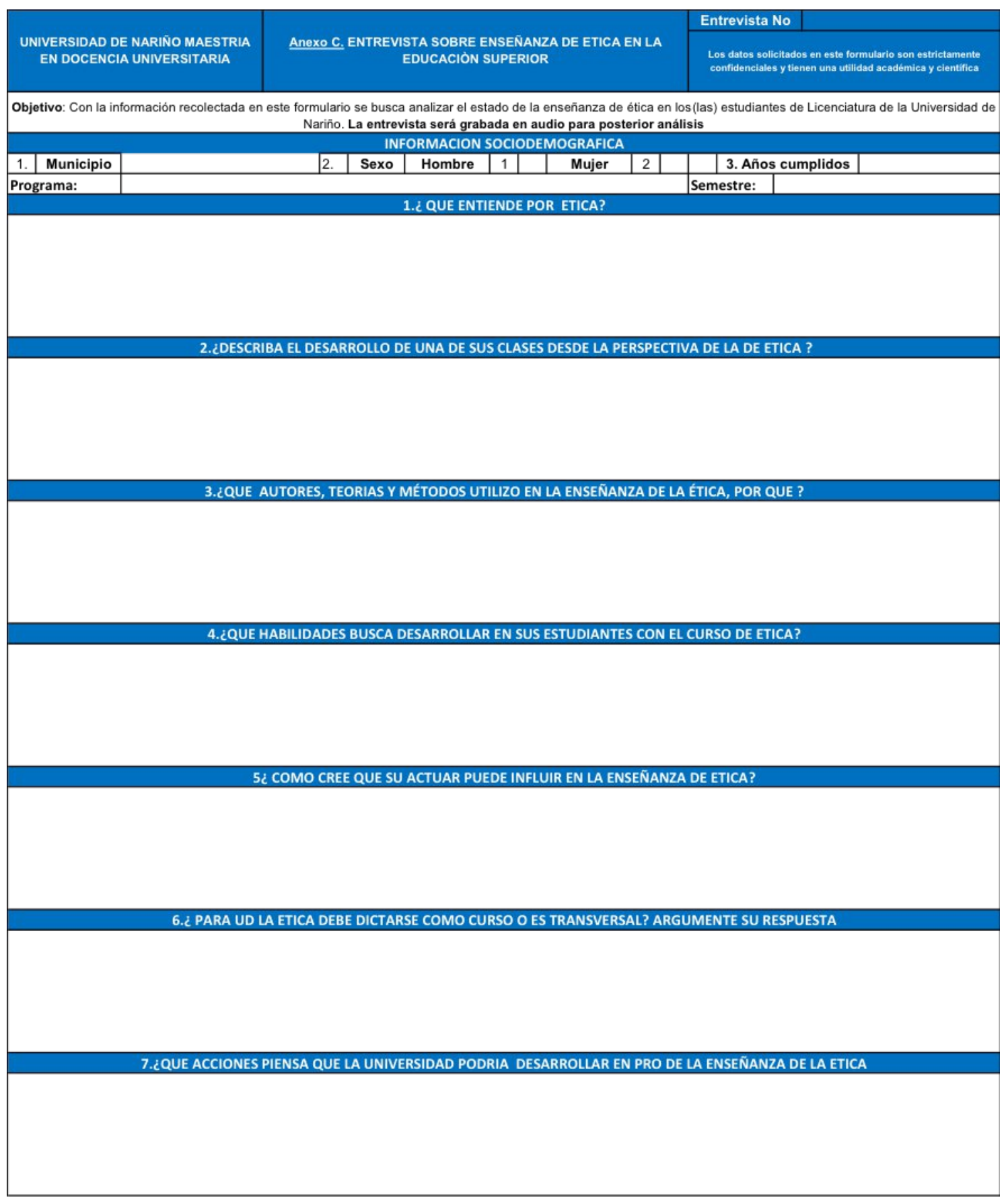

Muchas Gracias por su Colaboración.

\section{Fuente: elaboración propia}


nos y directores de los programas de Licenciatura de la Universidad de Nariño que conocen de manera general como se constituyen los programas que dirigen.

En total se realizaron 11 entrevistas: 4 entrevistas a directivos docentes de las licenciaturas de: Lic. Ambiental, Lic. Castellano y Literatura, Lic. Inglés y Francés, Lic. Inglés y Literatura y Lic. en Filosofía y Letras; 2 entrevistas a los decanos (as) de Educación y Ciencias Humanas y 5 entrevistas a representantes estudiantiles de los programas de Licenciatura.

\section{RESUltados \& DiscusióN}

Respecto a expectativas de enseñanza de la ética los estudiantes entrevistados consideran que la enseñanza debería salir de las aulas a través de trabajos de campo que permitan desarrollar el sentido de pertenencia y responsabilidad social en la personas, de esta forma se espera que los cursos relacionen la teoría con las practica. De igual manera, consideran necesario que los cursos de ética aporten al desarrollo de habilidades de socialización para mantener buenas relaciones con los otros.
En las expectativas sobre enseñanza de la ética, el estudiante de Licenciatura en Castellano y Literatura considera que deben enseñarse valores que aporten a moldear el comportamiento de las personas en buenos hábitos $\mathrm{y}$ el desarrollo de habilidades respecto a relaciones interpersonales, el saber escuchar, tener buenas relaciones con los otros como sus principales.

La representante estudiantil de la Licenciatura en Educación Ambiental y Ciencias Naturales tiene como expectativas que la enseñanza de la ética se relacione al diario vivir, a partir del reforzamiento de actitudes positivas. De igual manera, se espera que la enseñanza de la ética trascienda el aula donde el profesor enseñe con su comportamiento

Las expectativas que se forma la representante del programa de Licenciatura de Inglés y Francés es aprender actitudes reflexivas, desarrollar habilidades que les permita abordar problemáticas de los estudiantes desde aspectos psicológi$\cos$ y morales antes de enfrentarse 
a las prácticas profesionales. Resalta la necesidad de desarrollar bases de escucha, de tolerancia y respeto por las diversas opiniones que tienen las personas.

Como expectativa de enseñanza de ética, la representante estudiantil del programa de Licenciatura en Español e Inglés considera que debería dirigirse hacia la formación integral del profesional, que le permita enfrentar problemáticas $y$ dilemas éticos dentro de cada centro de educación a los que se enfrenta el futuro docente. Una de las habilidades que considera se debe desarrollar es la empatía "como docentes no ver al estudiante como una tabla rasa, se debe conocer el contexto en el que se desarrollan. (D. G, Entrevista, noviembre 2018)

Entre las expectativas que se tiene de la enseñanza de ética, la estudiante del programa de Licenciatura en Filosofía y Letras menciona que le gustaría que los estudiantes estén en contacto con la comunidad, de igual forma precisa que es necesario que en los procesos de enseñanza de ética que adelante la universidad se incluya a los padres de familia a partir de reuniones que les permita estar enterados del proceso de aprendizaje que tienen sus hijos.

La representante estudiantil de Programa de Filosofía y Letras sostiene que la enseñanza de la ética, es un proceso constante que debería incluirse en cada proceso de la universidad, desde la orientación profesional que debe brindar, en el desarrollo de actividades artísticas $y$ el fomento de actividades que incentivan el arte y la cultura, lo cual aporta al desarrollo de los valores.

En relación al papel del docente, la estudiante de Filosofía y Letras considera que el ejemplo debe caracterizarlo en el fomento de valores y principios éticos en los estudiantes, a partir de su propio actuar que debe ir más allá del dictar una materia, "se debe trasmitir la vocación del docente" (J.T, Entrevista, noviembre 2018) y como tal sostiene que la ética debe estar en los diferentes procesos de formación y manejarse de forma interdisciplinar. 
De acuerdo a las opiniones de los estudiantes, la enseñanza debe dirigirse a fortalecer habilidades positivas de los estudiantes, rescatar principios y valores de las personas. De igual manera, incentivar el desarrollo de comportamiento y hábitos sociales que permitan interactuar con el otro.

Como establece Ospina (2012) la responsabilidad de las instituciones va más allá de lo técnico y se encamina más en la formación de ciudadanos capaces de entender la grandeza de las cosas que se tienen dentro de la globalización radical que desconoce la importancia de los valores en la integración de la sociedad, para ello se requiere una estrecha relación entre la teoría y la práctica, que permita poner en acción los valores necesarios para convivir con los demás. Entre las categorías que emergen son la ética como vivencia y como reflexión.

Ética como vivencia: se refiere a enseñar la ética a partir de situaciones prácticas, de forma interactuada con los otros, tiene que ver con el desarrollo de cátedras que relacionen la teoría con la práctica. La ética como vivencia es tomarla como un proceso constante de formación que debe incluir valores y principios de socialización y compromiso social, lo cual coincide con postulados de Morín (1999) sobre la importancia de impartir principios pertinentes para la sociedad.

Morín comprende la importancia de enseñar la comprensión" y "la ética del género humano", para la convivencia social. De esta forma se requiere que desde las aulas los docentes desarrollen en los estudiantes principios y valores que les permita generar ambientes de tolerancia en base a la ética humana. (Morín 1999, p 73)

Aquí, toma relevancia otro aspecto de la teoría de Morín (1999), que se refiere a la eficacia de los procesos educativos, donde las disciplinas deben replantear su función, la cuestión de la especialización no es dividir el conocimiento si no que a partir de cada disciplina se genere un conocimiento integral para lograr procesos de cambio y superación de problemáticas sociales. 
Ética como reflexión: se refiere a procesos de enseñanza dirigidos a la reflexión de problemáticas sociales que afectan a las personas actualmente, es una reflexión del que hacer de cada persona, de la incidencia de sus actos en la sociedad y el compromiso que tienen en las problemáticas sociales que se viven.

La ética como reflexión se relaciona a la teoría de Moralla (2005) quien se refiere a la ética como la conciencia de los individuos, diferenciándola de la deontología, que se mueve preferentemente en el campo de los criterios compartidos por el colectivo profesional. El desarrollo de una formación ética desde Moratalla debe dirigirse al fomento de sentimientos colectivos, donde la comunidad adquiere más solidez y prácticas de sociabilidad.

Por su parte en lo que respecta a las expectativas que tienen los directivos docentes sobre la enseñanza de ética, se relacionan al desarrollo de competencias comunicativas y críticas en los estudiantes para que aporten a la resolución de conflictos sociales desde el desarrollo de valores. De igual forma, tienen como expectativas el desarrollo de habilidades adaptativas en los estudiantes que les permita interactuar dentro de un contexto educativo.

Como expectativas el decano de la Facultad de Educación considera que el perfil del docente debe ser adecuado para la formación del futuro profesional, el cual debe aplicar estrategias psico-sociales innovadoras que relacionen a los estudiantes con la realidad, es decir lo vivencial. Deben tener en cuenta los problemas de contexto, las condiciones a las cuales se puede enfrentar el futuro docente como son estudiantes en condición de discapacidad, resalta la importancia de incentivar el trabajo en grupo.

Entre las expectativas que tiene el director del programa de Licenciatura en Ciencias Naturales y Educación Ambiental, es que la ética debe existir en las mallas curriculares como asignatura y además de ello debe estar presente en cada área de estudio, dado que la falta de ética ha llevado a una crisis de 
las sociedades "la ética debe reforzase en los centros de educación superior, dado que los futuros profesionales son quienes tomaran la rienda de la nación." (C.P, Entrevista, noviembre 2018)

Las expectativas que se plantea la directora del programa en Lic. en Lengua Castellana y Literatura es que los estudiantes desde el curso de ética profesional desarrollen competencias comunicativas, habilidades para la vida e interacción con los estudiantes. De igual forma, se busca desarrollar en los estudiantes "habilidades que les permita incidir en los Manuales de Convivencia donde ellos van actuar" (M.V, Entrevista, noviembre 2018)

Las expectativas desde la decanatura de la Facultad de Ciencias Humanas respecto a la enseñanza de ética es desarrollar competencias del ser que se relacionen a valores y se busca incluir la ética en los semestres a través de debates que se espera fomenten el respeto a la diferencia y la valoración del otro.
Respecto a las expectativas de la enseñanza de la ética, el director del programa de Licenciatura en $\mathrm{Fi}$ losofía y Letras, comprende que la enseñanza de la ética debe aportar a la resolución de dilemas éticos, de comportamiento social a partir de la reflexión de películas. Las expectativas giran en torno al fortalecimiento de habilidades de resolución de conflictos sociales.

Como expectativas la directora del programa de Lingüística e Idiomas tiene que el desarrollo de la asignatura de Ética y Pedagogía con ayuda de la Facultad de Educación, corresponda a la formación integral de los estudiantes y no se quede como un proceso de costura de forma desconectada, para ello se tiene en cuenta el plan de mejora donde se plantea la ética profesional.

En general las expectativas se dirigen a que la enseñanza de la ética desarrolle en los estudiantes habilidades que les permita desenvolverse en un campo educativo donde se van a encontrar con una serie de dilemas éticos, para lo cual se requiere que los futuros 
profesionales puedan aplicar principios y valores desde competencias comunicativas y de reflexión en el ejercicio de la docencia.

La enseñanza de ética desde los docentes se relaciona a postulados de Nussbaum (2015), para quien su principal preocupación es que ciertas habilidades sociales están en riesgo de perderse, habilidades cruciales para la salud interna de cualquier democracia, y para la creación de una cultura mundial capaz de abordar de manera constructiva los problemas más apremiantes del mundo.

Estas habilidades están asociadas con las humanidades y las artes: la capacidad de pensar de manera crítica; la capacidad de trascender las lealtades locales y acercarse a los problemas mundiales como un "ciudadano del mundo"; y la capacidad de imaginar comprensivamente la situación del otro. (Nussbaum, 2015)

Una de las categorías que emergen es la habilidad en ética para la resolución de conflictos.
Habilidad en ética para la resolución de conflictos: se refiere al desarrollo de competencias comunicativas y de reflexión crítica que den habilidades a los estudiantes para desenvolverse en un campo social. Se pretende desarrollar habilidades que resuelvan conflictos y dilemas éticos por parte de los futuros licenciados, en lo que se refiere a decisiones que afectan a todo un grupo o a alguien, que requiere del desarrollo de principios de correspondencia y de responsabilidad social.

El desarrollo de habilidades en ética para la resolución de conflictos desde Nussbaum (2015) y Cortina (2013) debe permitir rescatar lo que nos queda. Sí bien los problemas presentes en la sociedad dependen de entes sociales, no ahí que desconocer que la solución está en los valores que promuevan las instituciones y en los mismos seres humanos.

En relación a las expectativas de estudiantes y docentes acerca de la enseñanza de ética en la universidad coinciden en que se aborde desde procesos reflexivos en el au- 
Tabla 3.Triangulación de información

\begin{tabular}{|c|c|c|}
\hline \multirow{3}{*}{$\begin{array}{l}\text { Expectativas } \\
\text { de enseñanza } \\
\text { de la ética }\end{array}$} & Entrevista a estudiantes & Entrevista a docentes \\
\hline & $\begin{array}{l}\text { Ética como vivencia: se } \\
\text { refiere a enseñar la ética a } \\
\text { partir de situaciones } \\
\text { prácticas, de forma } \\
\text { interactuada con los otros, } \\
\text { tiene que ver con el } \\
\text { desarrollo de cátedras que } \\
\text { relacionen la teoría con la } \\
\text { práctica. La ética como } \\
\text { vivencia es tomarla como un } \\
\text { proceso constante de } \\
\text { formación que debe incluir } \\
\text { valores y principios. }\end{array}$ & \\
\hline & $\begin{array}{l}\text { Ética como reflexión: se } \\
\text { refiere a procesos de } \\
\text { enseñanza dirigidos a la } \\
\text { reflexión de problemáticas } \\
\text { sociales que afectan a las } \\
\text { personas actualmente, es una } \\
\text { reflexión del que hacer de } \\
\text { cada persona, de la } \\
\text { incidencia de sus actos en la } \\
\text { sociedad y el compromiso } \\
\text { que tienen en las } \\
\text { problemáticas sociales que se } \\
\text { viven. }\end{array}$ & $\begin{array}{l}\text { Habilidad en ética para la } \\
\text { resolución de conflictos: se } \\
\text { refiere al desarrollo de } \\
\text { competencias comunicativas } \\
\text { y de reflexión crítica que den } \\
\text { habilidades a los estudiantes } \\
\text { para desenvolverse en un } \\
\text { campo social. Se pretende } \\
\text { desarrollar habilidades que } \\
\text { resuelvan conflictos y dilemas } \\
\text { éticos por parte de los futuros } \\
\text { licenciados. }\end{array}$ \\
\hline
\end{tabular}

\section{Fuente: elaboración propia}

la, donde se discutan problemáticas sociales y procesos que aporten a la formación integral de los estudiantes. De igual forma, sostienen que un curso de ética debe dirigirse al desarrollo de habilidades que resuelvan conflictos y dilemas éticos a los que se pueden enfrentar los futuros profesionales.

El desarrollo de habilidades como la asertividad para la resolución de conflictos y dilemas éticos a los que se pueden enfrentar los estudiantes en su práctica profesional y como tal al ejercer su profesión, se relacionan a los planteamientos de Morín (1999) sobre la pertinencia de enseñar la acción humana para enfrentar la incertidumbre y como tal enseñar la comprensión y la ética del género humano.

La ética del género humano se relaciona con los procesos de enseñanza a partir del fomento de es- 
pacios de tolerancia que permiten reflexionar acerca de temáticas sociales desde diálogos democráticos que contribuyen al crecimiento humano y a la concientización de los problemas que le rodean. Como menciona Cortina (2013) existe una necesidad indiscutible de una concientización social. Aporta al principio de responsabilidad, de hacerse cargo de las problemáticas sociales y contribuir a su solución.

De esta manera, entre las expectativas que se plantean docentes y estudiantes sobre la enseñanza de la ética esta principalmente el abordaje de problemas sociales que permitan sensibilizar y activar el sentido de pertenencia de las personas en relación a lo que ocurre en la actualidad para lo cual se requiere de procesos de reflexión crítica, que aporten al desarrollo profesional y personal de los estudiantes.

En relación a las expectativas que tienen los estudiantes y directivos docentes para la enseñanza de la ética se encuentra el trabajo de procesos reflexivos dentro y fuera de las aulas, donde se discutan problemáticas de contexto. De igual forma, los estudiantes sostienen que es importante que un micro currículo de ética se dirija al desarrollo de habilidades que resuelvan dilemas éticos a los que se pueden enfrentar los futuros profesionales.

El desarrollo de habilidades como la asertividad para la resolución de conflictos y dilemas éticos a los que se pueden enfrentar los estudiantes en su práctica profesional y en sí al ejercicio de su profesión, se refieren a la pertinencia de enseñar la condición humana de la comprensión para enfrentar la incertidumbre.

En sí las expectativas de enseñanza de la ética se dirigen al desarrollo de habilidades y valores en los futuros profesionales para afrontar problemas de contexto en los cuales pueden estar inmersos. Se refiere como tal al fomento de buenas conductas en los futuros profesionales a partir de la academia como espacio de interacción y formación integral. 


\section{CONCLUSIONES}

Respecto a la enseñanza de ética la mayor parte de estudiantes y docentes coinciden que debe basarse en la relación entre teoría y práctica, es decir que la enseñanza de ética debe ser vivencial en cada espacio de las aulas y la universidad. De igual forma resaltan la necesidad de desarrollar valores de pertenencia y responsabilidad que aporten a la resolución de problemas desde cada persona.

En cuanto a las expectativas que se plantean docentes y estudiantes sobre un curso de ética esta principalmente el abordaje de problemas sociales que permitan sensibilizar a las personas y activar el sentido de pertenencia de lo que ocurre en la actualidad, para lo cual se requiere de procesos de reflexión crítica que aporten al desarrollo profesional y personal de los estudiantes.

La enseñanza de ética es un aspecto fundamental a tener en cuenta en la reflexión constante que se realice de problemáticas sociales, ante las cuales la academia no puede ser indiferente, debe comprometerse con el fomento de principios $y$ valores que permitan ser un frente a problemáticas tales como la violencia y la corrupción.

La enseñanza de la ética requiere de la relación entre teoría y práctica de principios y valores, para el fomento de espacios de tolerancia y respeto entre los estudiantes. Como tal, la enseñanza de la ética desde la práctica se constituye como un aspecto de formación integral en las personas, que se ve explícito en su accionar.

\section{BIBLIOGRAFÍA}

Cortina. A. (2013). ¿Para qué sirve realmente la ética?. España: Paidós.

Morín, E. (2009). Los siete saberes necesarios para la educación del futuro. Francia: Organización de las Naciones Unidas para la Educación, la Ciencia y la Cultura -7 place de Fontenoy - 75352 París 07 SP

Moralla, A. (2005). Ética de las profesiones y formación universitaria: tres modelos de responsabilidad profesional. Colombia: Revista de Fomento Social

Nussbaum, M. (2015). El duro discurso sobre el futuro de la educación mundial. Colombia

Ospina, W. (2012). La tercera piedra después del sol. Colombia 